\title{
Are Laser Manufacturers Blue with Envy?
}

\section{Charles T. Whipple}

\section{Blue (or purple) diode lasers should hit the market this year and change all the rules in consumer electronics, data storage, printing and displays}

Lyricists have been infatuated with blue for centuries. Songs speak of blue eyes, blue velvet, blue angels and singing the blues. Scientists' and engineers' love affair with blue light, however, hearkens back only a few decades, to the 1960 s and the invention of semiconductor lasers.

\section{Laser Sources}

\section{Günter Huber, Hamburg University Jean-Pierre Huignard, Thomson CSF, France}

Compact and efficient diode pumped solidstate laser sources in the near infrared and visible spectral region are required for many applications such as measurement techniques, communications, and surgery. Besides $\mathrm{Nd}^{3+}$, various efficient diodepumped near infrared rare earth lasers have been operated with $\mathrm{Er}^{3+}, \mathrm{Tm}^{3+}, \mathrm{Ho}^{3+}$ and $\mathrm{Yb}^{3}$. Compact solid-state lasers in the visible spectral region are of potential interest, especially for display, medical, and high-density optical data storage applications. Recently, optical efficiencies of more than 20 per cent with respect to the pump power were obtained in $\mathrm{Nd}: \mathrm{Y}_{3} \mathrm{Al}_{5} \mathrm{O}_{12}$, $\mathrm{Nd:}: \mathrm{YVO}_{4}$, and $\mathrm{Nd}: \mathrm{LaSc}_{3}\left(\mathrm{BO}_{3}\right)_{4}$ lasers by internal frequency doubling with a

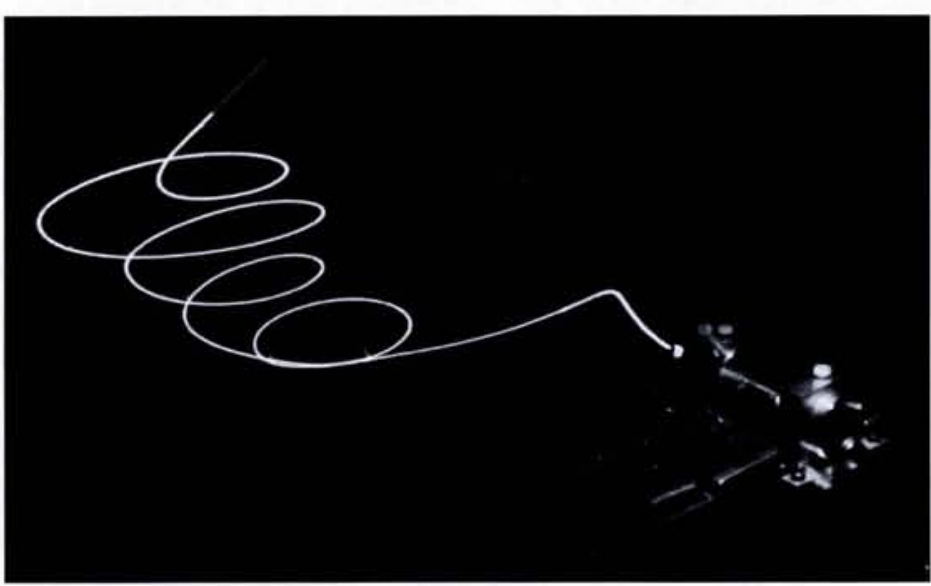

They thought they'd found the key in 1969 when RCA Laboratories in Princeton, in the US, developed crystalline thin films of gallium nitride. But the next step was 22 years in coming.

Thin-film semiconductors must be grown on a substrate, and the substrate's lattice - the spacing between its atoms must be an almost perfect match for the semiconductor's lattice. Gallium nitride grows at temperatures near $1000^{\circ} \mathrm{C}$, a factor that further limits possible substrates. In fact, only two materials match both lattice and temperature requirements: silicon carbide and sapphire. The former is prohibitively expensive, and the latter's lattice doesn't match ideally. Early on, sapphire substrates caused so many defects in the gallium nitride semiconductor layer that devices wouldn't lase.

Then, in 1986, Isamu Akasaki and his Nagoya University research group laid down a sacrificial layer of aluminum nitride on the sapphire, and topped it with a smooth layer of gallium nitride. The team also discovered how to make p-doped gallium nitride by adding continued over page potassium titanyl phosphate (KTP) crystal. An alternative approach for the realization of visible laser sources is up-conversion pumping by energy transfer processes of two adjacent excited ions or two step pump processes as ground state plus excited state absorption.

\section{Up-conversion Lasers}

Lasers which emit at higher frequencies than the pump light usually are called upconversion lasers. In these lasers the active ion is excited by internal up-conversion of near infrared or red light via multistep photon excitation or cooperative energy transfer and emits anti-Stokes visible light. The advent and rapid improvement of high power laser diodes in the red and near infrared spectral ranges have caused new interest in the development of upconversion lasers. The output wavelength of laser diodes can be tuned to match the absorption lines of the active laser ion, resulting in a substantial fraction of ions

Photograph of the 1.1 Watt continuous wave up-conversion fibre laser showing the pump input coupling optics, the fibre, and the red output (dark grey fibre tip, top left of picture) excited into higher energy levels, thus enhancing the up-conversion process.

Visible up-conversion lasing at room temperature has already been demonstrated in Tm-doped crystals and in various rare earth doped fluorozirconate fibres. $\mathrm{Er}^{3+}$ is a very interesting ion for continuous wave $(\mathrm{cw})$ up-conversion to the green spectral region.

Recently, research teams at Hamburg and Hannover demonstrated a cw Pr, Ybfibre up-conversion laser with $1.1 \mathrm{~W}$ output power at $635 \mathrm{~nm}$ (see photo). This device was pumped with $5.5 \mathrm{~W}$ Ti-sapphire radiation near $850 \mathrm{~nm}$. The pump mechanism in the ZBLAN-fibre is mainly due to avalanche up-conversion. High power diode pumping of this system seems also feasible.

The ions $\mathrm{Tm}^{3+}, \mathrm{Er}^{3+}, \mathrm{Pr}^{3+}$ provide upconversion schemes which lead to visible $\mathrm{cw}$ laser operation with near infrared pumping. The simple scheme of up-conversion lasers make them attractive candidates for further research.

The beam quality of laser sources can be improved by efficient phase conjugate laser architectures based on 4 wave-mixing interactions using two different nonlinear mechanisms: the gain gratings in saturable amplifiers, and the photorefractive gratings in doped $\mathrm{BaTiO}_{3}$ crystals. Both mechanisms have shown excellent capabilities for the correction of severe spatial aberrations. A nearly diffraction limited beam was obtained even when the average power and the repetition rate of the source was varied. Both configurations are attractive for compact and efficient diode pumped solid-state lasers with a diffraction limited beam quality. 
magnesium and annealing it with electron beams.

A young Japanese researcher named Shuji Nakamura watched Akasaki's work with interest. Employed by a small company, Nichia Chemical Industries in Tokushima, Japan, Nakamura had spent more than a decade playing catch-up with Japan's big electronics companies. He developed red light-emitting diodes (LEDs) for Nichia, but his heart was all blue. 'I decided to do research on blue LEDs,' Nakamura explained, 'because they had long been a dream of mine, going back to the days when I was doing LED materials research on $\mathrm{GaP}$ in $1979 . '$

After a year at the University of Florida in the US, learning how to grow crystals with metallorganic chemical vapour deposition, Nakamura returned to Nichia to take up his search for a blue laser in earnest. 'At that time, I tried not to read the [scientific] papers on III-V nitrides,' he said. 'Instead, I followed up on the lessons I learned from my experiments.'

It took Nakamura two years to achieve a breakthrough: his two-flow method of growing GaN films. Once that barrier was broken, his advances came in virtual leaps and bounds: p-doping of GaN, InGaN growth, blue LEDs introduced in 1995 and now blue lasers. Today, Nakamura's blue GaN lasers have operated in continuouswave mode for more than 4000 hours at elevated temperatures, which extrapolates to approximately 10,000 hours at room temperature.

\section{Quest for the Blue}

Nakamura's breakthroughs, first with LEDs and then with blue lasers, triggered a rash of blue laser programs around the world. Although a few companies sell blue LEDs, only two are close to commercializing blue diode lasers. When he was interviewed in early March, Nakamura was adamant that Nichia will be shipping samples of its blue lasers by the end of the year. Only one other company - Japan's Matsushita Electric Industrial Co. - seems to be that close to the market.

Matsushita's blue laser uses a tuneable distributed Bragg reflector $830 \mathrm{~nm}$ laser, and a second harmonic generator to create a $415 \mathrm{~nm}$ beam. The key component is a 10 $\times 0.5 \times 0.5 \mathrm{~mm}$ chip of MgO-doped $\mathrm{LiNbO}_{3}$ material that's 'not so expensive,' said Ryoichi Imanaka, general manager of product planning and development in Matsushita's optical disc systems division.

Nakamura said Nichia's lasers would cost less than ¥1000 (7 Ecus), and
Matsushita is ready to match that price. Down the road, however, as production volume increases, it will be easier for Nichia to reduce prices on its simple semiconductor laser than for Matsushita to cut the cost of its more complicated device.

Some say Nichia is two years ahead of the pack, but that may not be true. Manijeh Razeghi and colleagues at Northwestern University, Illinois in the US, have demonstrated continuous-wave (CW) room-temperature operation of $\mathrm{InGaN} / \mathrm{GaN}$ multiquantum-well lasers, observing no considerable degradation in laser characteristics during lifetime testing of 140-plus hours. Cree Research of Durham, North Carolina in the US, also has achieved a CW blue laser beam, but so far its duration is only a few seconds.

Several university and corporate labs have achieved pulsed blue lasers: Boston University, the University of California at Santa Barbara, Hewlett-Packard Co., the Xerox Palo Alto Research Center and SDL in the United States; and Meijo University, Toshiba, Fujitsu and Pioneer in Japan. Some use GaN, some use silicon carbide substrates and some offer double heterostructure for greater efficiency.

In one interesting development, Leo Schowalter and his group of researchers at Rensselaer Polytechnic Institute in Troy, New York State in the US, found a way to grow aluminum nitride crystals large enough to be sliced into semiconductor substrates. Schowalter pointed out that because aluminum nitride endures extreme heat, it can be used for microelectronic devices on jet engines.'

Hearing of the development, Nichia's Nakamura said, 'If they've found something good, they'll come to us.'

\section{Why Blue?}

The market for this technology is hot because of its potential impact in commercial markets. Business Communications in Connecticut in the US, reported that sales of blue and true green LEDs and laser diodes amounted to $\$ 189.5$ million (170 million Ecus) in 1997 but should hit \$950.5 million (860 million Ecus) in 2000, an average annual growth rate of 38.1 per cent.

Where will that money come from? Gerhard Fasol, president of Eurotechnology Japan, said, 'Blue lasers have large ready-made commercial markets: displays, high-density data storage, laser printing, communications and lighting, to name a few. There may well be several other applications that have yet to be imagined.'

Business Communications agrees with
Fasol on data storage and laser printing and adds surgery, contaminant detection and covert communications as possibilities. In addition, the US Navy has said it is interested in blue lasers for optical communication through water; seawater absorbs less blue light than longer wavelengths. Other possibilities include flat screen displays and projection TVs.

Blue LEDs offer nearly as many possibilities, some of which have already been realized. There's a full-colour display made of 300,000 red, green and blue LEDs at Hachiko Square near bustling Shibuya Station on Tokyo's Yamanote commuter train line. At the moment, LED colour displays are commercially competitive with projected displays when the diagonal measurement exceeds 2.5 meters. But they may soon be competitive at 1.25 meters.

Most colour copiers use fluorescent light when scanning, but true blue light sources could lead to significant improvements in colour scanners and even colour facsimile machines.

In The Blue Laser Diode, a book by Fasol and Nakamura, Fasol writes that LEDs are likely to replace incandescent light bulbs in traffic signals. This year, a number of LED traffic lights have been put into test operation in Japan to see how they work in various weather conditions. The Japanese government has an ongoing program to replace incandescent and fluorescent lighting with LEDs. Nichia already markets white LEDs that could replace conventional room lighting.

'Biological applications of LEDs are very interesting to me,' said Nakamura. 'You see, plants only need red and blue light for photosynthesis. Tests show that plants grow up to five times as fast under red and blue LED light. Think what that means for space stations.'

\section{Feeding Consumers' Desires}

The most significant market for blue diode lasers, however, is in consumer electronics.

In 1979, Sony's beta format was battling it out with Matsushita's VHS for supremacy in the infant home videocassette recorder market. Consumers had bought nearly a million players, and experts wondered if VCRs would be the consumer electronics successor to colour TV sets.

Similarly, in the music market, compact discs drove vinyl records off music store shelves and reduced the appeal of cassette tapes. Even the music hit product of our times, Walkman, went to $\mathrm{CD}$ versions.

Now the consumer electronics industry is preparing for another battle, this time 
over digital video disc players. Electronics companies hope that a new generation of digital video disc products will take over from VCRs as CDs have taken over the cassette tape market.

Think back once more to the videocassette recorder wars: Beta vs. VHS. Did VHS win because it was the better format? The answer depends on whose story you're listening to. But the nail in the beta coffin was VHS's longer recording time. Beta's two-hour tapes just weren't long enough.

The same situation is true in the new war. Compact disc players use $780 \mathrm{~nm}$ diode lasers to read and write the information on an optical medium. The first-generation digital video disc players used red lasers at 630 to $635 \mathrm{~nm}$. The shorter wavelength allowed them to pack more information on a single disc. Some manufacturers had wanted to wait for blue lasers, rather than release the $630 \mathrm{~nm}$ machines, but most electronics manufacturers figured it would be the 21st century before blue lasers were commercially available. And they didn't feel they could sit on the digital video disc until then.

GaN-based blue laser development happened a lot faster than anyone guessed. Progress with blue lasers prompted manufacturers to announce a standard for new-generation digital video discs during the Joint Magneto-Optical Recording International Symposium and International Symposium on Optical Memory 1997 in Yamagata, Japan, in October. The group chose to set the blue laser wavelength standard at $410 \mathrm{~nm}$. At the meeting, Sony and Pioneer unveiled new-generation players that use blue lasers. The rest of Japan's electronics companies are at their heels.

Why the rush? In November, digital broadcasts of high-definition television will start in the US. Developers of new-generation digital recorders want to be able to store more than two hours of high-definition entertainment on one disc the size of a current $\mathrm{CD}$. To do that, each disc must hold $15 \mathrm{~GB}$ of information. That will require blue lasers.

\section{New Standards on the Way}

As soon as the blue lasers are available commercially, you can bet consumer electronics manufacturers will plug them into red laser heads and start testing and adjusting. Imanaka of Matsushita said his company has already developed a 15 GB system with one of its second harmonic generator laser devices. Expect proposals for specific new-generation standards in late 1998 and early 1999. Right now, every company seems to have its own ideas, but they'll be ironed out before long. And unlike current digital recording systems, the new-generation products will read and write.

'Ideally, DVD-RAM units using blue-purple lasers will read CD information,' said Matsushita's Nobuo Akahira. Getting them to rewrite the red lasers' data is more problematic: Blue lasers with their tiny wavelengths don't completely erase the larger pits made by red lasers.

\section{Better Printing}

The printing industry must be considered from two viewpoints: laser printing that transfers toner to paper, and printing presses that use plates to transfer ink to paper.

At the Materials Research Society meeting last year in the US, Ross Bringans of the Xerox Research Center in California reported that the world digital printing market should reach $\$ 100$ billion (9o billion Ecus) by 2000 . He said consumers are increasingly demanding speed, colour, high resolution, power efficiency and multiple functions such as scanner, facsimile and laser printer in a single unit.

Blue diodes offer smaller spot sizes, good depth of field and adequate optical aperture. According to Bringans, $780 \mathrm{~nm}$ red laser diodes require expensive, bulky 12 $\mathrm{mm}$ aperture optics and large polygon scanners to achieve 1200 dpi resolution. Furthermore, the depth of field is only 0.5 $\mathrm{mm}$. A $390 \mathrm{~nm}$ blue laser, on the other hand, could achieve 1200 dpi and $1 \mathrm{~mm}$ depth of field with $6 \mathrm{~mm}$ optics. What's more, Bringans said laser printers would need only $6 \mathrm{~mW}$, single-mode, continuous-wave diodes.

Curt Frederickson, marketing manager of the OEM Business Unit at Spectra-Physics Lasers in California, said that a decade ago image setters used silver halide film that was exposed with low-power blue light. Cheap red diodes prompted development of red-sensitive film, and the industry moved in that direction. 'I do not see them returning to blue, not just because red diodes are cheaper, but because volume has made red-sensitive film cheaper, too,' he said.

High-speed digital printers used blue LEDs for a while, Frederickson added. But now they use infrared diodes. Still, he said, 'colour laser printers might go to blue for resolution, if the price is right.'

A market also may exist for blue or green lasers in the computer-to-plate process. To achieve the necessary speed, the lasers would have to emit at 50 to $100 \mathrm{~mW}$. But they'll have to hurry; Frederickson said the market is moving toward infrared-exposure plate materials.

According to Robert Melcher of IBM's Watson Research Laboratory in New York state in the US, laser diodes also offer tremendous potential for full-colour flat panel displays and projection televisions. At the Materials Research Society meeting, Melcher pointed out that polarized monochromatic laser light eliminates the need for polarizing optics, eases the specification requirements of other optical elements and makes it easier to filter out ambient light. $\mathrm{He}$ also said field-sequential colour techniques that use pulsed laser diodes to overlay red, green and blue images could replace the current three-beam system. The result would be a more saturated image with a broader range of colours.

\section{In Full Colour}

Melcher's hypothetical projection TV assumed that the photonics industry would develop $656 \mathrm{~nm}$ red, $532 \mathrm{~nm}$ green and $457 \mathrm{~nm}$ blue diodes. This combination would produce a $6500 \mathrm{~K}$ white-point colour balance. A 1.25 metre screen would require $6.6 \mathrm{~W}$ of blue, $1.8 \mathrm{~W}$ of green and $1.2 \mathrm{~W}$ of blue laser light.

The necessary red diodes already exist, but the Internet Journal of Nitride Semiconductor Research reported, 'If blue and green wavelengths are to be provided by laser diodes, GaN lasers must be extended to longer wavelengths and their output power drastically improved. Although Nichia has supplied blue and green $\mathrm{GaN}$ LEDs since 1995, extending laser diode wavelengths to the visible will be more difficult.'

Nichia's Nakamura said he can easily alter his lasers' wavelengths by controlling the amount of indium in the InGaN layer. 'The power is coming,' he said confidently.

The excitement lit by the possibilities of blue lasers permeates the electronics industry. Still, blue lasers are not a panacea, but a starting point.

In the words of Spectra-Physics' Frederickson: 'Blue diodes will definitely have an impact in ion laser markets, but if the red diode vs. HeNe wars teach us a lesson, it is that the transition will not be as quick as the blue diode advocates would like us to believe.'

Reprinted from the May 1998 issue of Photonics Spectra (c)Laurin Publishing Co. For subscription information visit www.PhotonicsNet.com 